\title{
DE UNIEKE ENKELING EN ZUJN EIGENDOM
}

\author{
Max Stirner
}

Redaktionele inleiding

In 1844 verschïnt bï de uitgever Otto Wigand, Leipzig, het hoogst eigenaardige boek Der Einzige und sein Eigentum van Max Stirner, pseudoniem van Johann Caspar Schmidt. Het boek wekte schandaal en heel wat wijsgeren, onder wie Karl Marx en Friedrich Engels, hebben zich tegen dit boek afgezet. Het is een extreem pleidooi voor het egoisme in ethisch, metafysisch en politiek opzicht. Het is eigenlijk zo extreem dat de meeste mensen zich precies niet meer met het denken van Stirner konden identificeren, hoewel toch gesteld kan worden dat de auteur juist die teneur van de menselïke neigingen en zelfs overwegingen expliciteert die men tot uiting zou willen brengen. Misschien is de Westerse filosofie van Aristoteles over Hobbes tot het hedendaagse post-moderne denken met zïn esthetico-individualisme. in moreel opzicht wel heel eng met Stirner verwant. Men moet maar aan de aristotelische autarkiegedachte denken of aan de hedendaagse zelfontplooiingsideologie. Maar wat Stirner van zün collega's - eigenlijk wel scherper dan Friederich Nietzsche - onderscheidt, is het feit dat hij alle hoogdravende woorden wil ontmaskeren. Hï houdt wel heel hardnekkig het IK over.

Niet veel wijgeren hebben total anders gedacht. Drie namen uit de moderne wijsbegeerte zijn hier op hun plaats : Kant, Kierkegaard en Levinas. Het boek Totalité et Infini, waarvan eerstdaags een nieuwe Nederlandse vertaling verschijnt (Baarn, Ambo), kan ongetwijfeld als de meest radikale tegenhanger van Der Einzige und sein Eigentum worden genoemd, en het is ongetwijfeld onder meer de verdienste van Stephan Strasser geweest die tegenstelling te reveleren/The Unique Individual and His Other, in: Analecta Husserliana vol. VI. Dordrecht, Reidel, 1977, blz. 9-26). Het boek van Max Stirner valt echter niet zo maar te weerleggen, althans niet met een ideologische doctrine of een wijsgerig traktaat. Stirner beschrijft een levenshouding, waaraan een geloof ten grondslag ligt. Slechts in de praktük kan de onwaardigheid van die grondslag worden aangetoond - althans bü diegene die het verlangen kent om een andere grondslag in 
zichzelf te voltrekken. Met wat men ideologie en wetenschap noemt, geraakt men in dit perspectief niet ver. Nogmaals, wijsheid en praktisch inzicht, phronèsis, zijn deugden van het dagelijks leven en ontstaan niet conceptueel in een laboratorium of zijn niet het produkt van een computer.

De redaktie van De Uil van Minerva biedt hier een fragment, de eerste bladzijden, uit het beruchte boek van Stirner omdat men met dit werk kennis moet maken. De vertaling is van de hand van Charles Rossie die zich in dit herzingen al meer verdienstelijk heeft gemaakt (Nietzsche, Hölderlin, Baudelaire) en kan hier in een zekere zin als een pre-publicatie worden beschouwd. Alleen heeft de vertaler voor zijn integrale vertaling nog geen uitgever gevonden. Als men Ayer of Skinner in het Nederlands vertaalt en uitgeeft, waarom niet Stirner ?

Aan Mijn Liefie Marie Dähnhardt

Ik heb Mijn Zaak

op Niets gevest

Wat moet niet allemaal Mijn Zaak zijn! Bovenal de goeie Zaak, dan de Zaak Gods, de Zaak van de Mensheid, van de Waarheid, van de Vrijheid, van de Humaniteit, van de Gerechtigheid; voorts de Zaak van Mijn Volk, van Mijn Prins, van Mijn Vaderland; tenslotte ook nog de Zaak van de Geest en duizend andere Zaken. Alleen Mijn Zaak moet nooit Mijn Zaak zijn. 'Foei zo'n egoisst die alleen maar aan zichzelf denkt!'

Laten Wij dus even toekijken hoe diegenen met hun Zaak omspringen voor wier Zaak Wij moeten werken, $W_{i j}$ overgave en geestdrift horen op te brèngen.

Jullie weten over God veel fundamenteels te verkondigen en hebben duizenden jaren lang 'de dieptes van de Godheid doorvorst' en in haar hart naar binnen gekeken, zodat Jullie Ons wel kunnen zeggen hoe God de 'Zaak Gods', die Wij geroepen zijn te dienen, zelf versiert. En Jullie verhelen haar ook niet, de sier van de Heer. Wat is nou zijn Zaak ? Heeft hij, zoals het van Ons wordt gevergd, een vreemde Zaak, heeft hij de Zaak van de Waarheid, van de Liefde tot de zijne gemaakt ? Jullie zijn verontwaardigd om dit misverstand en Jullie beduiden Ons dat Gods Zaak uiteraard de Zaak van Waarheid en Liefde is, maar dat zij niet een zaak kan worden genoemd die hem vreemd zou zijn, omdat God immers zelf de Waarheid en Liefde is; Jullie zijn verontwaard igd bij de veronderstelling dat God op Ons, arme wormen, zou kunnen lijken, door een vreemde Zaak als eigene naar voren te brengen. 'God zou zich de Zaak van de Waarheid moeten aantrekken, indien hij niet zelf de Waarheid zou zijn'? Hij zorgt enkel voor zijn Zaak, 
maar omdat hij Alles bij elkaar is, daarom is ook alles zijn Zaak ! Wij echter, Wij zijn niet Alles bij elkaar, en onze Zaak is erg klein en verachtelijk; daarom moeten Wij een 'hogere Zaak dienen'. - Nou, het is duidelijk, God bekommert zich enkel om 't $\mathrm{Zijne}$, is alleen maar met zichzelf bezig, denkt alleen maar aan zichzelf en heeft alleen maar zichzelf op het oog; wee Alles wat hem niet welgevallig is. Hij dient niet iets hogers en bevredigt enkel zichzelf. Zijn Zaak is een - puur egoistische Zaak.

Hoe is het gesteld met de Mensheid, wier Zaak Wij tot de onze horen te maken ? Is haar Zaak wellicht die van iemand anders en dient de Mensheid een hogere Zaak ? Nee, de Mensheid heeft alleen aandacht voor zichzelf, de Mensheid wil alleen de Mensheid vooruithelpen, de Mensheid heeft aan zichzelf haar Zaak. Opdat zij zich zou kunnen ontwikkelen, laat zij volken en individuen in haar dienst zich afsloven en kwellen, en wanneer die gepresteerd hebben wat de Mensheid nodig heeft, dan worden zij door haar uit dankbaarheid op de vaalt van de geschiedenis gegooid. Is de Zaak van de Mensheid niet een - puur egoistische Zaak?

Ik hoef helemaal niet aan ieder die zïn Zaak naar Ons toe zou willen schuiven, te tonen dat hij zich alleen maar om zichzelf, niet om Ons, alleen maar om zijn eigen welzijn, niet om het Onze bekreunt. Kijkt naar de overigen maar eens. Verlangt de Waarheid, de Vrijheid, de Humaniteit, de Gerechtigheid iets anders dan dat Jullie enthousiast gaan doen en hen dienen ? $\mathrm{Zij}$ varen er allemaal biezonder wel bij, wanneer hen met grote ijver en plichtsbetrachting hulde wordt bewezen. Bekijkt nu eens het volk dat door toegewijde patriotten wordt beschermd. De patriotten vallen in de bloedige strijd of in de strijd tegen honger en nood; wat laat het volk zich daaraan gelegen liggen ? Het volk wordt door de mest van hun lijken een 'bloeiend volk'! De individuen zijn 'voor de grote Zaak van het volk' gestorven, en het volk stuurt hen een paar woorden van dank achterna en - strijkt het profijt op. Dat is wat ik noem een winstgevend egoisme.

Maar kijkt toch naar die fameuze sultan, die voor 'de Zijnen' zo liefdevol zorgt. Is hij niet de pure onbaatzuchtigheid zelf en offert hij zich niet uur na uur voor de Zijnen ? Precies, voor 'de Zijnen'. Probeer het een keer en vertoon Jou niet als de Zijne, maar als de Jouwe: Je zal, omdat Jij Jezelf aan zijn egoisme onttrok, in de kerker terechtkomen. De sultan heeft zijn Zaak op Niets dan op zichzelf gevest: hij is voor zichzelf Alles bij elkaar, is voor zichzelf de enigunieke en duldt niemand die het zou bestaan niet één van de 'Zijnen' te zijn. En uit deze schitterende voorbeelden willen Jullie niet leren dat de egoist de beste beurt maakt ? Ik voor Mijn part trek daar lering uit en wil, eerder dan die grote egoisten nog verder onbaatzuchtig te dienen, liever zelf de egoist zijn. God en de Mensheid hebben hun Zaak op Niets gevest, op niets dan op Zichzelf. Laat Ik dan mijn Zaak eveneens op Mezelf vesten. Ik die net $z 0$ goed als God het Niets 
van al het Andere, Ik die mijn Alles, Ik die de enig-unieke enkeling ben. Heeft God, heeft de Mensheid, zoals Jullie verzekeren, inhoud genoeg in zich om voor zichzelf Alles bij elkaar te zijn: dan merk Ik dat het $M i j$ hieraan nog veel minder zal schorten, en dat ik over mijn 'leegheid' niet zal hoeven te klagen. Ik ben niet Niets in de zin van een leegheid, maar het scheppende Niets, het Niets van waaruit Ik zelf als schepper Alles schep. Weg dus met elke Zaak die niet heel en al Mijn Zaak is! Jullie vinden dat Mijn Zaak tenminste de 'goeie Zaak' zou moeten zijn ? Wat betekent goed, wat kwaad! Ik ben immers zelf Mijn Zaak, en Ik ben noch goed noch kwaad. Allebei hebben zij voor Mij geen zin. Het Goddelijke is Gods Zaak, het Menselijke Zaak 'van de Mens'. Mijn Zaak is noch het Goddelijke noch het Menselijke, is niet het Ware, Goede, Passende, Vrije enzovoort, maar alleen het Mijne, en zij is er geen van algemene aard, maar is - enig-uniek, zoals Ik enig-uniek ben.

Voor Mij gaat niets boven Mezelf !

\section{EERSTE GEDEELTE}

\section{De Mens}

De Mens is voor de Mens het hoogste wezen, zegt Feuerbach.

De Mens is nu pas gevonden, zegt Bruno Bauer.

Laten Wij dus dit hoogste wezen en deze nieuwe vondst wat nauwkeuriger gaan bekijken.

\section{Een Mensenleven}

Vanaf het moment dat hij het licht van de wereld aanschouwt, probeert een mens uit haar wirwar, waarin ook hij samen met al het andere kriskras heen en weer wordt gegooid gelijk een dobbelsteen, weg te raken, zichzelf te vinden en zichzelf te winnen.

Doch op zijn beurt stelt alles wat met het kind in aanraking komt, zich tegen diens ingrepen te weer en affirmeert $z$ ijn eigen bestaan.

Derhalve is, omdat ieder het voor zichzelf opneemt, en tevens met het andere onophoudelijk in botsing komt, de strijd voor zelfaffirmatie onvermijdelijk.

Overwinnen of Het-onderspit-delven, - tussen beide wisselvalligheden schommelt de strijdkans. De overwinnaar wordt de heer, de verliezer de onderdaan: de een doet zijn soevereiniteit en 'soevereine rechten' gelden, de ander vervult met ontzag en respect zijn 'plichten als onderdaan'. 
Maar vijanden blijven allebei en liggen altijd op de loer: zij loeren op elkaars zwakheid, kinderen op die van hun ouders, en ouders op die van hun kinderen (bijvoorbeeld hun vrees), ofwel triomfeert de stok over de mens of de mens triomfeert over de stok.

In de kinderjaren verloopt de bevrijding op zo'n manier dat $\mathrm{Wij}_{\mathrm{ij}}$ op de bodem van de dingen of 'achter de dingen' proberen te komen: daarom leggen $\mathrm{Wij}_{\mathrm{j}}$ ons oor te luisteren om bij allen hun zwakheden op het spoor te komen, waarvoor zoals bekend kinderen een feilloos instinct hebben, daarom breken Wij graag dingen stuk, doorsnuffelen graag verborgen hoekjes, speuren naar zaken die omfloerst en weggemoffeld zijn, en beproeven Onze krachten op alles. Pas wanneer $W_{i j}$ er echter zijn gekomen, weten $W_{i j}$ dat We veilig zijn; zijn Wij bijvoorbeeld er achter gekomen dat de roe het moet afleggen tegen Onze vastberadenheid, dan vrezen Wij haar niet meer, 'zijn haar ontgroeid'.

Achter de roe staat, machtiger dan zij, onze - vastberadenheid, onze vastberaden moed. Wij komen allengs achter alles wat Ons onheilspellend en vreemd leek, achter de onheilspellende gevreesde macht van de roe, de strenge tronie van vader enzovoort, en achter alles vinden $W_{i j}$ Onze - ataraxie, dat wil zeggen onwrikbaarheid, onverschrokkenheid, onze tegenautoriteit, overmacht, onbedwingbaarheid. Wat Ons eerst vrees en respect inboezemde, daarvoor trekken $W_{i j}$ Ons niet meer schichtig terug, maar vatten moed. Achter alles vinden $W_{i j}$ Onze moed. Onze superioriteit; achter het barse bevel van meerderen en ouders staat toch Ons moedig goedvinden of Onze listige schranderheid. En hoe meer Wij Onszelf voelen, des te kleiner blijkt datgene wat voordien onoverkoombaar leek. En wat is Onze list, schranderheid, moed, vastberadenheid? Wat tenzij dan -Geest!

Een hele tijd lang blijft Ons een strijd, die Ons later zozeer opeist, bespaard, de strijd tegen de rede. De mooiste kinderjaren gaan voorbij zonder dat Wij met de rede slag zouden hoeven te leveren. Wij bekommeren Ons helemaal niet om haar, laten Ons met haar niet in, verstaan geen rede. Door overtuiging brengt men Ons tot niets, en tegenover goede redenen, principes enz. zijn wij doof; aan liefkozingen, kastijdingen en dies meer weerstaan Wij daarentegen moeilijk.

Deze bittere levensstrijd met de rede komt pas later aan bod, en dat is het begin van een nieuwe fase: in de kinderjaren stoeien $W_{i j}$ er op los, zonder veel te piekeren.

Geest heet de eerste zelfvinding, de eerste ontgoddelijking van het goddelijke, dat wil zeggen van het onheilspellend vreemde, van het spookbeeld, van de 'hogere machten'. Nu laat ons fris jeugdgevoel, dit zelfgevoel, zich door niets meer imponeren: de wereld is gediscrediteerd, want Wij zijn boven haar, zijn geest.

$\mathrm{Nu}$ pas zien $W_{i j}$ dat $W_{i j}$ de wereld totnogtoe helemaal niet met geest hebben 
bekeken; alleen maar aangestaard.

Aan natuurkrachten meten $W_{i j}$ Onze eerste sterkte. Ouders imponeren Ons als natuurkracht; later luidt het: vader en moeder moeten worden verlaten, alle natuurkracht moet als verbroken worden beschouwd. Je bent hen te boven. Voor de met-Rede-toegeruste, dat wil zeggen 'met-Geest-toegeruste mens' bestaat er geen familie als natuurkracht: tot uiting komt een afwijzen van ouders, broers en zussen, enzovoort. Wanneer die als geestelijke, redelijke krachten 'herboren' worden, dan zijn zij volstrekt niet meer datgene wat zij voordien waren.

En niet enkel de ouders, maar de mensen als zodanig worden door de jonge mens overwonnen: zij zijn voor hem geen hinderpaal, en er wordt met hen geen rekening meer gehouden: want, zo luidt het nu: Je moet aan God meer gehoorzamen dan aan de mensen.

$\mathrm{Al}$ het 'aardse' wordt onder dit hoge standpunt naar een verachtelijke verte teruggedrongen: want het standpunt is het - hemelse.

De houding is nu totaal omgekeerd, de jongeling neemt een geestelijke houding aan, terwijl de knaap, die zich nog niet als geest voelde, in een geesteloos leerproces opgroeide. De jongeling probeert niet de dingen te bemachtigen, bijvoorbeeld niet de historische gegevens in zijn hoofd te stoppen, maar hij wil de gedachten te pakken krijgen die in de dingen verborgen liggen, zo bijvoorbeeld de geest van de geschiedenis; de knaap daarentegen verstaat wel verbanden, maar niet ideeën, de geest; daardoor rijgt hij zaken die geleerd kunnen worden, aan elkaar, zonder apriorisch en theoretisch tewerk te gaan, dat wil zeggen zonder naar ideeën te zoeken.

Waar je in je kinderjaren de weerstand van de wereldwetten de baas moest kunnen worden, krijg je nu bij al wat je van plan bent, te maken met een tegenspraak van de geest, van de rede, van het eigen geweten. 'Dat is onredelijk, onchristelijk, onpatriottisch en dergelijke meer, roept Ons het geweten toe, en schrikt Ons ervan af. - Niet de macht van de wrekende Eumeniden, niet de toorn van Poseidon, niet de God, al ziet hij ook het verborgene, niet de tuchtroe van de vader vrezen $W_{i j}$, maar het - geweten.

Wij 'geven Ons nu over aan Onze gedachten' en volgen net zo hun geboden op als Wij voorheen de ouderlijke, menselijke geboden opvolgden. Onze daden richten zich volgens onze gedachten (ideeën, voorstellingen, geloof), zoals in de $k$ inderjaren volgens de bevelen van de ouders.

Wel hebben Wij ook als kinderen reeds gedacht, met dit verschil echter dat onze gedachten niet vleesloos, abstract, absoluut waren, dat wil zeggen niets anders dan gedachten, een hemel op zichzelf, een pure gedachtenwereld, logische gedachten.

Integendeel waren het alleen maar gedachten geweest die $W_{i j}$ Ons over een zaak vormden: Wij dachten dat het ding zus of zo was. Wij dachten dus wel: 
de wereld die Wij daar zien, is door God gemaakt; maar Wij dachten ('doorvorsten') niet de 'dieptes van de Godheid zelf'; Wij dachten wel: 'dat is het Ware wat die zaak betreft', maar Wij dachten niet het Ware of de Waarheid zelf, en gingen niet het verband leggen door één enkele zin te formuleren 'God is de Waarheid'. De 'dieptes van de Godheid, die de Waarheid is', raakten Wij niet aan. Bij zulke puur logische, dat wil zeggen theologische kwesties: 'Wat is Waarheid' blijft Pilatus niet stilstaan, ofschoon hij in een afzonderlijk geval daarom niet aarzelt om aan de weet te komen 'wat er Waar is in de zaak', dat wil zeggen of de zaak waar is.

Elke aan een zaak gebonden gedachte is nog niet niets anders dan gedachte, absolute gedachte.

De pure gedachte te voorschijn halen, of je eraan hechten, dat is jeugdpret, en alle lichtgestaltes van de gedachtewereld, zoals Waarheid, Vrijheid, Mensdom, de Mens enzovoort inspireren de jeugdige ziel en maken haar geestdriftig. Maar wanneer de geest als het wezenlijke is erkend, dan maakt het toch een verschil of de geest arm dan wel rijk is, en men probeert daarom rijk aan geest te worden: de geest wil zijn domein uitbreiden om zijn rijk te vestigen, een rijk dat niet van deze wereld is, waarboven men net is uitgestegen. En zo hunkert hij er dan naar om alles bij elkaar te worden, dat wil zeggen ofschoon Ik geest ben, ben Ik toch niet voltooide geest, en moet de volmaakte geest eerst nog zoeken.

Maar daarmee verlies $\mathbf{I k}$, die Me daarnet als geest had gevonden, meteen Mezelf weer, doordat Ik tegenover de volmaakte geest, tegenover een geest die Mij niet eigen is maar aan de 'overkant' in het hiernamaals, in 'de andere wereld' bestaat, Mij buig en mijn leegheid gevoel.

Op geest komt het weliswaar overal aan, maar is ook elke geest de 'passende' geest ? De passende en ware geest is het ideaal van de geest, de 'heilige geest'. Hij is niet Mijn of Jouw geest, maar juist een - ideale, aan-de-overkant-bestaande geest, hij is 'God', 'God is geest'. En deze in het hiernamaals-bestaande 'vader in de hemel geeft hem aan wie tot hem bidden'.

Het onderscheidt de man van de jongeling, dat hij de wereld neemt zoals die is, eerder dan haar overal in de macht van de Boze te wanen en te willen verbeteren, dat wil zeggen volgens zijn ideaal te willen modelleren; in hem wordt de opvatting verstevigd dat je met de wereld moet omspringen vanuit je belang, niet vanuit je idealen.

Zolang je je alleen maar als geest situeert en al je waarde erin vindt geest te zijn (voor de jongeling valt het makkelijk zijn leven, het 'lichamelijke', leven om een nietigheid op te offeren, om de onnozelste krenking), zolang heb je ook alleen maar gedachten, ideeën, waarvan je hoopt dat je hen, wanneer je een invloedssfeer hebt gevonden, in werkelijkheid om zult kunnen zetten; je hebt dus vooralsnog alleen maar idealen, onvoltrokken ideeën of gedachten. 
Pas dan, wanneer je jezelf in levenden lijve hebt leren liefhebben, en aan jezelf, zoals je leeft en lijfelijk streeft, plezier.beleeft - en zoiets tref je aan op rijpe leeftijd, bij de man - pas dan heb je een persoonlijk(e) of egoistisch(e) belang(stelling), dat wil zeggen een interesse niet zomaar voor Onze geest alleen, maar voor totale bevrediging, bevrediging van de hele vent, een baatzuchtige interesse. Vergelijkt toch een keer een man met een jongeling, of hij Jullie niet harder, ongrootmoediger, baatzuchtiger zal lijken. Is hij daarom slechter? Jullie zeggen Nee, hij is alleen maar beslister, of, zoals Jullie het ook noemen, 'praktischer' geworden. Hoofdzaak echter is dit, dat hij zichzelf meer tot middelpunt maakt dan de jongeling het doet, die met andere dingen, bijvoorbeeld God, Vaderland en dat soort dingen meer, 'dweept'.

Daarom vertoont de man een tweede zelfvinding. De jongeling vond zichzelf als geest en verloor zichzelf weer ten voordele van de algemene geest, de volmaakte, heilige geest, de mens, de mensheid, kortom alle idealen; de man vindt zich als lijfgeworden, 'baarlijke' geest.

Knapen hadden alleen maar ongeestelijke, dat wil zeggen gedachteloze en ideeënloze, jongelingen alleen maar geestelijke belang(stellingspunt)en; de man heeft 'baarlijke', persoonlijke, egoïstische belangen.

Wanneer het kind niet een voorwerp heeft waarmee het zich bezig kan houden, dan voelt het verveling: want het weet nog niet hoe het met zichzelf bezig kan zijn. Andersom gooit de jongeling het voorwerp aan de kant, omdat hij vanuit het voorwerp gedachten kreeg: hij houdt zich bezig met zijn gedachten, zijn dromen, houdt zich geestelijk (mentaal) bezig of 'zijn geest is bezig'.

Al wát niet van de geest is, vat de jonge mens samen onder de misprijzende naam 'uiterlijkheden'. Als hij dan toch aan de kleinste uiterlijkheden blijft hangen, bijvoorbeeld studentikoze of andere formaliteiten), dan gebeurt zoiets omdat en wanneer hij in hen geest ontdekt, dat wil zeggen wanneer zij voor hem 9 symbolen zijn.

Zoals Ik Mezelf achter de dingen vind, en wel als geest, zo moet Ik Mezelf later ook achter de gedachten vinden, namelijk als hun schepper en eigenaar. In de geestentijd groeiden Me de gedachten boven het hoofd, waarvan zij toch de voortbrengsels waren; zoals koortsfanta sieën zweefden zij rondom Mij en grepen Me aan, een huiveringwekkende macht. De gedachten waren op zichzelf lijfelijk geworden, waren spoken, zoals God, Keizer, Paus, Vaderland enzovoort. Als Ik hun lijfelijkheid vernietig, dan neem Ik haar weer in de Mijne terug en zeg: Ik alleen ben lijfelijk. En nu neem en beschouw Ik de wereld als datgene wat zij voor Mij is, als de Mijne, als Mijn eigendom: Ik betrek alles op Mezelf.

Stootte Ik als geest de wereld met diepste wereldverachting terug, dan stoor Ik als eigenaar de geesten of ideeën weer terug in hun 'ijdelheid'. Zij hebben geen macht meer over $\mathrm{Mij}$, net zoals over de geest geen 'Macht van de aarde' een macht heeft. 
Het kind was realistisch, in de dingen van deze wereld bevangen, tot het hem allengs gelukte er achter te komen wat nu juist deze dingen 'om het lijf' hadden; de jongeling was idealistisch, door gedachten geestdriftig gemaakt, tot hij zich omhoog werkte om een egoistisch man te worden, die met de dingen en gedachten naar hartelust omspringt en zijn persoonlijk belang boven alles stelt. Tenslotte dan nog de grijsaard? Als ik er een word, dan is er nog tijd genoeg om daarover te praten.

(vertaling Charles Rossie)

\section{AGENDA}

In de Gentse Kultuurvereniging gaan in het voorjaar nog drie lezingen door: maandag 20 januari: Dr. Koen Raes over 'Intersubjectiviteit en moraal'; maandag 17 februari: Dr. Roger Burggraeve over 'Levinas, intersubjectiviteit en ethiek'; maandag 10 maart: Dr. Julien Quackelbeen over 'De overgang van het imaginaire naar het symbolische in de relatie tot de andere'. De lezingen gaan door om 20 uur in het auditorium van de HBK-Spaarkas, Lammerstraat 18, 9000 Gent.

Op woensdag 23 april geeft Dr. Julia Kristeva een publieke les over 'Le sens de la mélancholie' in het auditorium van de Facultés Universitaires Saint-Louis Kruidtuinlaan 43 te Brussel (om 20u30).

Twee lezingen in de Universitaire Faculteiten Sint-Aloysius (Vrijheidslaan 17, 1080 Brussel/Koekelberg): op zaterdag 1 februari te 14u30: Dr. G. Theys over 'Agressiviteit, ingeboren of aangeleerd ?'; en op zaterdag 15 februari te 14u30: Dr. Rob Devos over 'Lichaam als bron' van macht: Michel Foucault'. 